\title{
Use of antidepressants near delivery and risk of postpartum hemorrhage: cohort study of low income women in the United States
}

\author{
Kristin Palmsten postdoctoral research fellow ${ }^{1}$, Sonia Hernández-Díaz associate professor ${ }^{1}$, Krista \\ F Huybrechts instructor ${ }^{2}$, Paige L Williams senior lecturer ${ }^{3}$, Karin B Michels associate professor ${ }^{145}$, \\ Eric D Achtyes assistant professor ${ }^{6}$, Helen Mogun programmer ${ }^{2}$, Soko Setoguchi associate \\ professor $^{17}$
}

'Department of Epidemiology, Harvard School of Public Health, 677 Huntington Avenue, Boston, MA 02115, USA; ${ }^{2}$ Division of Pharmacoepidemiology and Pharmacoeconomics, Department of Medicine, Brigham and Women's Hospital and Harvard Medical School, 1620 Tremont Street, Suite 3030, Boston, MA 02120, USA; ${ }^{3}$ Department of Biostatistics, Harvard School of Public Health, 677 Huntington Avenue, Boston, MA 02115, USA; ${ }^{4}$ Obstetrics and Gynecology Epidemiology Center, Department of Obstetrics, Gynecology, and Reproductive Biology, Brigham and Women's Hospital, Harvard Medical School, 221 Longwood Avenue, Boston, MA 02115, USA; ${ }^{5}$ Institute for Prevention and Cancer Epidemiology, University of Freiburg Medical Center, Freiburg, Germany; ${ }^{6}$ Division of Psychiatry and Behavioral Medicine, College of Human Medicine, Michigan State University, 100 Cherry Street SE, Grand Rapids, MI 49503, USA; ${ }^{7}$ Duke Clinical Research Institute, Duke University School of Medicine, 2400 Pratt Street, Durham, NC 27705, USA

\begin{abstract}
Objective To determine whether use of serotonin or non-serotonin reuptake inhibitors near to delivery is associated with postpartum hemorrhage.

Design Cohort study.

Setting 2000-07 nationwide Medicaid data (Medicaid Analytic eXtract). Population 106000 pregnant women aged 12-55 with a diagnosis of mood or anxiety disorder. Women were categorized into four mutually exclusive exposure groups according to pharmacy dispensing data: current (delivery date), recent (1-30 days before delivery date), past (1-5 months before delivery date), and no exposure (reference group).

Main outcome measures Risk of postpartum hemorrhage by timing of exposure and by serotonin or non-serotonin reuptake inhibitors, classes of antidepressant, and antidepressant types. Relative risks and 95\% confidence intervals adjusted for delivery year, risk factors for postpartum hemorrhage, indicators of severity of mood/anxiety disorder, other indications for antidepressants, and other drugs. High dimensional propensity score (hdPS) methods were used to empirically identify and adjust for additional factors.

Results 12710 (12\%) women had current exposure to serotonin reuptake inhibitor monotherapy, and 1495 (1.4\%) women had current exposure to non-serotonin reuptake inhibitor monotherapy. The risk of
\end{abstract}

postpartum hemorrhage was $2.8 \%$ among women with mood/anxiety disorders but no exposure to antidepressants, $4.0 \%$ in the current users of serotonin reuptake inhibitors, $3.8 \%$ in the current users of non-serotonin reuptake inhibitors, $3.2 \%$ in the recent users of serotonin reuptake inhibitors, $3.1 \%$ in the recent users of non-serotonin reuptake inhibitors, $2.5 \%$ in the past users of serotonin reuptake inhibitors, and $3.4 \%$ in the past users of non-serotonin reuptake inhibitors. Compared with no exposure, women with current exposure to serotonin reuptake inhibitors had a 1.47-fold increased risk of postpartum hemorrhage (95\% confidence interval 1.33 to 1.62) and women with current non-serotonin reuptake inhibitor exposure had a 1.39-fold increased risk (1.07 to 1.81). Results were similar with hdPS adjustment. Women with current exposure to serotonin reuptake inhibitors had an adjusted excess risk of $1.26 \%$ $(0.90 \%$ to $1.62 \%)$, with a number needed to harm of 80 , and for women with current exposure to non-serotonin reuptake inhibitors the excess risk was $1.03 \%(0.07 \%$ to $1.99 \%)$, with a number needed to harm of 97 . For exposure to serotonin reuptake inhibitors the relative risk was 1.19 (1.03 to 1.38) for recent exposure and 0.93 (0.82 to 1.06) for past exposure; for non-serotonin reuptake inhibitors the figures were 1.17 (0.80 to 1.70 ) and 1.26 (1.00 to 1.59 ), respectively. Current exposure to selective serotonin reuptake inhibitor monotherapy was also associated with postpartum hemorrhage $(1.42,1.27$ to 1.57$)$, as was current serotonin norepinephrine (noradrenaline) reuptake inhibitor (1.90, 1.37 
to 2.63$)$ and tricyclic monotherapy (1.77, 0.90 to 3.47). All types of selective serotonin reuptake inhibitors available for analysis and venlafaxine, a serotonin norepinephrine reuptake inhibitor, were significantly associated with postpartum hemorrhage.

Conclusions Exposure to serotonin and non-serotonin reuptake inhibitors, including selective serotonin reuptake inhibitors,

serotonin-norepinephrine reuptake inhibitors, and tricyclics, close to the time of delivery was associated with a 1.4 to 1.9-fold increased risk for postpartum hemorrhage. While potential confounding by unmeasured factors cannot be ruled out, these findings suggest that patients treated with antidepressants during late pregnancy are more likely to experience postpartum hemorrhage.

\section{Introduction}

Postpartum hemorrhage is a leading cause of maternal mortality in the United States and elsewhere ${ }^{12}$ and is a substantial contributor to severe maternal morbidity, blood transfusions, and admissions to intensive care. ${ }^{34}$ The incidence of postpartum hemorrhage has increased since the 1990s in the US (from 2.3\% to $2.9 \%$ between $1994-2006)^{5}$ and in several other developed countries.-8 This trend is not fully explained by temporal changes in the frequency of established risk factors for postpartum hemorrhage, including multiple pregnancy and induction and/or augmentation of labor. ${ }^{67}$ As postpartum hemorrhage is serious, the causes of this increase in incidence need to be identified.

Many, but not all, studies have shown that use of antidepressants that inhibit serotonin reuptake increase the risk of bleeding events, such as gastrointestinal and perioperative bleeding. ${ }^{9-14}$ Use of serotonin reuptake inhibitors is thought to increase risk of bleeding by depleting platelet serotonin. ${ }^{15}$ Between $7-13 \%$ of pregnant women in the US are treated with antidepressants. ${ }^{16-18}$ Only two studies, both in non-US populations, however, have investigated the association between antidepressants and postpartum hemorrhage. Salkeld and colleagues reported a 1.30-fold borderline significant increased risk of postpartum hemorrhage associated with use of a selective serotonin reuptake inhibitors in the 90 days before delivery, ${ }^{19}$ and Reis and colleagues reported a 1.45 -fold increased risk for bleeding during delivery in a comparison of any versus no use of antidepressants. ${ }^{20}$ While these studies raise concerns, they had limitations including potential confounding by mood disorders or factors associated with them, exposure windows that did not focus on delivery, and limited power to assess specific antidepressants.

Medicaid is the joint state and federal health insurance program for low income individuals in the US. Using nationwide Medicaid data, we assessed the association between exposure to antidepressants at the time of delivery and postpartum hemorrhage. We hypothesized that women exposed to serotonin reuptake inhibitors at the time of delivery would have an increased risk compared with those without any exposure, while women with serotonin reuptake inhibitor exposure only well before delivery and women exposed to non-serotonin reuptake inhibitors antidepressants would not have an increased risk. We accounted for the potential effect of underlying mood/anxiety disorders, considered exposure at the time of delivery (the likely relevant exposure period), classified antidepressant use according to serotonin transporter affinity, and evaluated risk of postpartum hemorrhage with respect to specific classes and types of antidepressants.

\section{Methods Eligible population}

We previously identified a cohort of pregnancies ending in live birth in 2000-07 Medicaid Analytic eXtract (MAX) data among women aged $12-55 .{ }^{21-23}$ To ensure claim completeness during the second half of the pregnancy, women were required to have Medicaid enrollment and meet eligibility criteria - that is, no private insurance, no restricted benefits, and appropriate type of enrollment from five months before delivery until after delivery. The eligible population included 2759414 pregnancies from 2340631 women.

\section{Mood and anxiety disorders}

We restricted the primary analyses to a subcohort of 106000 women with diagnoses for mood or anxiety disorders (as inpatients or outpatients; ICD-9 (international classification of diseases, ninth revision) code for 296.x, 300.x, 309.x, or 311.x) between one and five months before delivery (fig $1 \Downarrow$ ) to reduce the potential for confounding by unmeasured factors that are correlated with these disorders. The positive predictive value for depression with these codes was $77 \%,{ }^{24}$ indicating that most women in this subcohort likely had depression. We restricted a secondary analysis to women with diagnostic codes specific for depression - that is, those that did not include bipolar and anxiety disorders (ICD-9 codes: 296.2x, 296.3x, 296.9, 300.4x, 309.0x, 309.1x, 309.28, 311.x).

\section{Outcome}

Women with an ICD-9 code for 666.x during the admission to hospital for delivery, or within three days after the delivery date for outpatient deliveries, were classified as having postpartum hemorrhage. We also considered atonic postpartum hemorrhage only (666.1x; caused by inadequate uterine contraction $)^{25}$ and inpatient postpartum hemorrhage only.

\section{Exposure}

Most antidepressants are inactivated and eliminated within days to a week after use, ${ }^{26}$ yet the potential carry over effect on the risk of postpartum hemorrhage after discontinuation of is unknown. Consequently, we defined four mutually exclusive exposure groups based on the dispensing date of prescription and days' supply dispensed relative to the delivery date:

- Current exposure: women with a supply of antidepressants that overlapped with the delivery date

- Recent exposure: women with a supply of antidepressants on at least one day in the month before the delivery date but not on the delivery date

- Past exposure: women with a supply of antidepressants ending between five and one months before delivery

- Unexposed: women who had no supply of antidepressants in the five months before delivery (reference group).

Because the degree of inhibition of serotonin reuptake is thought to play a role in the association between antidepressants and abnormal bleeding events, ${ }^{9-14}$ we classified the exposure groups by serotonin transporter affinity with previously reported serotonin transporter dissociation constants $(\mathrm{Kd})^{27-29}$; a lower $\mathrm{Kd}$ reflects a higher affinity for the serotonin transporter. Antidepressants with serotonin transporter Kd 0-9.9 nM were classified as serotonin reuptake inhibitors and antidepressants with $\mathrm{Kd} \geq 10 \mathrm{nM}$ were classified as non-serotonin reuptake inhibitors (appendix 1). We considered only monotherapy with either type and therefore excluded from the primary analysis 
the 3278 women who were exposed to both drugs types (polytherapy) during the five months before delivery.

We considered also current, recent, and past exposure to specific antidepressants if at least 100 women with mood/anxiety disorders and current serotonin or non-serotonin reuptake inhibitor monotherapy were exposed to a given drug. Next we considered exposure to any antidepressant. We then defined exposure groups by class (appendix 1): selective serotonin reuptake inhibitor, serotonin norepinephrine (noradrenaline) inhibitor, tricyclic, bupropion, and other antidepressants, excluding from this analysis women exposed to more than one class.

\section{Covariates}

Baseline information on comorbidities and healthcare use was obtained from data between one and five months before delivery, before the recent and current exposure windows. Potential confounders included risk factors for postpartum hemorrhage $\mathrm{e}^{6-31}$ : delivery year, age (as a quadratic spline), race, multiple pregnancy, coagulopathies, diabetes (classified as diagnosis and no dispensing of antidiabetic drugs, no diagnosis but with dispensing, diagnosis and dispensing); proxies of mood/anxiety disorder severity (number of outpatient $(0,1,2-5,6-9, \geq 10)$ and inpatient $(0,1, \geq 2)$ diagnoses of mood/anxiety disorder); other indications for antidepressants (psychotic disorder, other mental health disorder, pain related diagnoses); use of other psychotropic drugs (anticonvulsants and benzodiazepines); other drugs associated with risk of bleeding (aspirin, heparin, and warfarin); and proxies of comorbidity (number of outpatient visits (quadratic spline) and days in hospital (0, 1-2, 3-4, 5-6, $\geq 7)$ ). ${ }^{32}$ Potential mediators of postpartum hemorrhage- that is, risk factors that could be affected by antidepressant use and consequently would not be confounders ${ }^{33}$ - included delivery characteristics (short labor, long labor, forceps or vacuum delivery, or induced labor ${ }^{6-31}$ ) as documented during the admission for delivery or within three days after the delivery date for outpatient deliveries.

\section{Statistical analysis}

We compared the risk for postpartum hemorrhage between women with exposure to antidepressants and the unexposed group using relative risks and risk differences and their corresponding $95 \%$ confidence intervals from generalized estimating equations. ${ }^{34}{ }^{35}$ Models were adjusted for potential confounders and robust variances were used to account for correlations among multiple pregnancies in the same woman. ${ }^{35}$ Furthermore, we used high dimensional propensity score (hdPS) methods to empirically identify and adjust for additional factors that might be surrogates for unmeasured confounders in the databases. ${ }^{36}{ }^{37}$ We excluded $2.5 \%$ of women on both extremes of the distribution of the propensity score and adjusted logistic regression models for 10ths of the score, which was estimated from investigator defined covariates and 200 empirically identified variables. To support the validity of our outcome definition, we also assessed the association between well established risk factors for postpartum hemorrhage and occurrence of postpartum hemorrhage. Because women in this cohort were younger and more racially diverse than those in previous studies, ${ }^{19}{ }^{20}$ we tested for multiplicative effect modification of current exposure by age $(\geq 30)$ and race/ethnicity (white and non-white). To determine if there was an indirect effect of current exposure to serotonin or non-serotonin reuptake inhibitors on postpartum hemorrhage through any of the measured delivery characteristics that are risk factors for postpartum hemorrhage, we performed a mediation analysis ${ }^{38} 39$ using estimates from logistic regression models for postpartum hemorrhage and for the delivery characteristics. All analyses were conducted with SAS software, version 9.2 for Windows (SAS Institute, Cary, NC).

\section{Sensitivity analyses}

We performed eight sensitivity analyses to evaluate the robustness of the results. Because obesity is associated with postpartum hemorrhage and is poorly measured by healthcare use data, we conducted a sensitivity analysis ${ }^{40}{ }^{41}$ to correct the relative risks for current use of serotonin and non-serotonin reuptake inhibitors for confounding by unmeasured obesity. Using data for women aged 18-55 with depression from the 2005-10 National Health and Nutrition Examination Survey (NHANES), we estimated the prevalence for obesity among those women who reported antidepressant use and those who reported no antidepressant use, accounting for the complex sampling design. ${ }^{42} \mathrm{We}$ assumed the relative risks for obesity and postpartum hemorrhage was between 1.5 and 2.0 for the obesity correction. ${ }^{43}$ Second, we repeated the primary analysis but included all women with and without mood/anxiety disorders ( $n=2759414$ pregnancies). Third, we restricted the study population to the 1248875 (45.3\% of the overall study population) women who met requirements for Medicaid enrollment and eligibility throughout pregnancy; baseline covariates were assessed with data between one month and nine months before delivery and the past exposure window began at nine months before delivery. Fourth, we restricted the cohort with mood/anxiety disorder diagnoses to women without a diagnosis of hypertension or use of antihypertensive drugs. While hypertension is a risk factor for postpartum hemorrhage, ${ }^{731}$ increased blood pressure can be a consequence of using certain antidepressants ${ }^{45}{ }^{46}$ so we avoided stratification by hypertension in the primary analysis. ${ }^{47}$ Fifth, in a dose analysis, we categorized women with current serotonin and non-serotonin reuptake inhibitor monotherapy according to the highest antidepressant dose that overlapped with the delivery date and compared them with women without exposure to antidepressants. Dose levels were defined according to Goodman and Gilman's usual dose (mg/day) $)^{26}$ : low is less than the lowest usual dose, medium is less than or equal to the midpoint of the usual dose range, high is more than the midpoint of the usual dose range (appendix 1). Because of small numbers, we combined medium and high doses for non-serotonin reuptake inhibitors. Sixth, we considered users of polytherapy in each exposure window-that is, women with current exposure to both serotonin and non-serotonin reuptake inhibitors-and determined their risk of postpartum hemorrhage compared with unexposed women. Seventh, we restricted the current exposure group to women who likely had the highest adherence - that is, those with exposure to the drug on more than $75 \%$ of days during the three months before delivery. Finally, in an exposure sensitivity analysis, we classified women with an antidepressant dispensed less than 14 days before delivery, regardless of days of supply on the delivery date, as having current exposure.

\section{Results}

Among pregnant women with mood/anxiety disorders, $15.1 \%$ had a supply of antidepressants that overlapped their delivery date. There were 12710 (12\%) women with current exposure to serotonin reuptake inhibitor monotherapy and 1495 (1.4\%) women with current exposure to non-serotonin reuptake inhibitor monotherapy. Compared with unexposed women, more women in the exposed groups were older and white and had 
hypertension, admission to hospital with a diagnosis of anxiety/mood disorders, other antidepressant indications, and other psychotropic drugs (table $1 \Downarrow$ ). There were, however, fewer differences in patients between groups defined by current, recent, and past exposures to serotonin and non-serotonin reuptake inhibitors. Overall, $91 \%$ of women delivered in a hospital. Among women who delivered in a hospital, 69\% delivered on the admission date and $95 \%$ delivered within one day of being admitted.

The risk of postpartum hemorrhage was $2.4 \%$ among women without diagnoses of mood/anxiety disorder and without exposure to antidepressants in the five months before delivery and $2.8 \%$ among women with mood/anxiety disorders but without exposure to antidepressants. The risk of postpartum hemorrhage was $4.0 \%$ in current users of serotonin reuptake inhibitors and $3.8 \%$ in current users of non-serotonin reuptake inhibitors; for recent users the risk was $3.2 \%$ and $3.1 \%$, respectively, and for past users risk was $2.5 \%$ and $3.4 \%$, respectively. Compared with women without each predisposing factor, women with pre-eclampsia (relative risk 1.43, 95\% confidence interval 1.26 to 1.64$)$, labor induction $(1.56,1.42$ to $1.72)$, and forceps or vacuum delivery $(1.39,1.21$ to 1.59$)$ had an increased risk for postpartum hemorrhage. After adjustment for potential confounders, compared with unexposed women, current users of a serotonin reuptake inhibitor had a 1.47-fold increased risk for postpartum hemorrhage (95\% confidence interval 1.33 to 1.62 ) and the current non-serotonin reuptake inhibitor monotherapy group had a 1.39-fold increased risk (1.07 to 1.81 ) (table $2 \Downarrow$ ). In absolute terms, women with current exposure to serotonin reuptake inhibitors had an adjusted excess risk of $1.26 \%(0.90 \%$ to $1.62 \%)$, with a number needed to harm of 80; the figure for women with current non-serotonin reuptake inhibitor exposure was $1.03 \%(0.07 \%$ to $1.99 \%)$, with a number needed to harm of 97 . Adjustment for additional potential confounders through hdPS analysis yielded odds ratios of 1.52 (1.35 to 1.71) for current use of serotonin reuptake inhibitors and 1.39 (1.03 to 1.89) for current use of non-serotonin reuptake inhibitors (table $3 \Downarrow$ ). For recent use of antidepressants, the relative risk was 1.19 (1.03 to 1.38) for serotonin reuptake inhibitor and 1.17 (0.80 to 1.70$)$ for non-serotonin reuptake inhibitor exposure. While the women with past exposure to serotonin reuptake inhibitor monotherapy did not have an increased risk for postpartum hemorrhage, in those with past exposure to non-serotonin reuptake inhibitor monotherapy the risk was slightly increased and nearly significant (table 2 ). $\Downarrow$

The risk of postpartum hemorrhage was associated with current exposure to specific serotonin reuptake inhibitor antidepressants, the highest risk being with venlafaxine (table $4 \Downarrow$ ). Compared with unexposed women, women with current exposure to any antidepressant had an increased risk for postpartum hemorrhage (relative risk 1.44, 1.32 to 1.58 ), as did women with any recent exposure (1.21, 1.06 to 1.38$)$, while women with any past exposure did not have an increased risk (table $5 \Downarrow$ ). As a class, current selective serotonin reuptake inhibitor monotherapy was associated with postpartum hemorrhage (1.42, 1.27 to 1.57$)$, as was current serotonin norepinephrine reuptake inhibitor (1.90, 1.37 to 2.63 ) and tricyclic monotherapy (1.77, 0.90 to 3.47 ).

There was evidence of multiplicative effect modification by age $(\mathrm{P}=0.02$ for the exposure-age interaction term); there was no association between current exposure to non-serotonin reuptake inhibitor and postpartum hemorrhage among women aged at least 30 (fig $2 \Downarrow$ and appendix 2). None of the delivery characteristics (short or long labor, instrumental delivery, labor induction) were substantial mediators of the current associations between serotonin or non-serotonin reuptake inhibitor and postpartum hemorrhage.

External adjustment for obesity attenuated the relative risks to between 1.3 and 1.4 for current serotonin reuptake inhibitors and about 1.3 for current non-serotonin reuptake inhibitors. A dose response was indicated for current exposure to serotonin reuptake inhibitors but not for non-serotonin reuptake inhibitors (table $6 \Downarrow)$. The relative risk was 1.42 (0.97 to 2.08) for current polytherapy, 1.68 (0.94 to 3.00) for recent polytherapy, and 0.93 ( 0.60 to 1.44 ) for past polytherapy. All other sensitivity analysis results are summarized in figure 2 (numbers and risks are listed in appendix 2). $\Downarrow$ The confidence intervals were wider for the non-serotonin reuptake inhibitor than the serotonin reuptake inhibitor groups. Past use of non-serotonin reuptake inhibitors was not associated with postpartum hemorrhage in the cohort of women both with and without diagnoses of mood/anxiety disorder and the cohort of women who met eligibility criteria throughout pregnancy and had mood/anxiety disorders. Women with the greatest amount of antidepressant coverage in the 90 days before delivery in the current serotonin reuptake inhibitor exposure group had a 1.54-fold increased risk of postpartum hemorrhage ( $95 \%$ confidence interval 1.36 to 1.76 ), and the corresponding relative risk for the current non-serotonin reuptake inhibitor exposure group was 1.25 (0.85 to 1.83 ). The relative risks ranged from 1.32 to 1.54 in current users of serotonin reuptake inhibitor monotherapy and from 1.31 to 1.69 for current users of non-serotonin reuptake inhibitor monotherapy when we changed the exposure and outcome definitions and when we restricted analysis to women with depression and without hypertension.

\section{Discussion}

In this population of pregnant women, use of serotonin or non-serotonin reuptake inhibitors at the time of delivery was associated with about a 1.4 to 1.5 -fold increase in risk of postpartum hemorrhage and $1.0 \%$ to $1.3 \%$ excess risk. Selective serotonin reuptake inhibitor, serotonin norepinephrine reuptake inhibitor, and tricyclic monotherapy at the time of delivery were associated with postpartum hemorrhage. Any exposure to antidepressants in the month before delivery was associated with about a 1.2-fold increased risk of postpartum hemorrhage. While exposure to serotonin reuptake inhibitors one to five months before delivery was not associated with postpartum hemorrhage, exposure to non-serotonin reuptake inhibitors during that time frame was associated with a nearly significant increased risk.

\section{Comparison with previous studies}

The association we found between selective serotonin reuptake inhibitor antidepressants and postpartum hemorrhage was slightly higher than that reported by Salkeld and colleagues from the Ontario administrative databases. ${ }^{19}$ Our exposure window covered only the delivery date, whereas their primary exposure window covered the 90 days before delivery. As suggested by our analysis of recent exposure, their exposure window could have been broader than the true exposure-risk window, possibly leading to downward bias. Our estimates were more precise than those from Ontario because of the large number of exposed cases. The association we found between any current exposure to antidepressants and postpartum hemorrhage was similar to the association between antidepressants prescribed during antenatal care and bleeding during delivery reported by Reis and colleagues. ${ }^{20}$ We attempted to reduce potential confounding by factors associated with 
underlying mood/anxiety disorders by restriction to women with diagnoses of mood/anxiety disorder, adjusting for proxies of severity of indication, and using high dimensional propensity score analysis whereas previous studies did not.

\section{Possible explanations of results}

We found no evidence that the delivery characteristics mediated the association. Along with cofactors, serotonin contributes to platelet aggregation, and the association between serotonin reuptake inhibitor and bleeding could be explained, at least in part, by the inhibition of serotonin reuptake by platelets, which cannot synthesize serotonin. ${ }^{15}$ Normally, excessive uterine bleeding from the site of placental implantation is prevented by uterine myometrial contraction. ${ }^{25}$ Serotonin reuptake inhibitors increase extracelluar serotonin concentrations, ${ }^{48}$ and the myometrium contracts in response to serotonin. ${ }^{49}$ Besides interfering with hemostasis, serotonin reuptake inhibitors could also interfere with serotonin mediated uterine contraction and contribute to atonic postpartum hemorrhage.

When we consider the hypothesis that the risk of bleeding increases with exposure to antidepressants that block serotonin reuptake,$^{50}$ the association between non-serotonin reuptake inhibitor monotherapy and postpartum hemorrhage is unexpected. The positive associations between both serotonin and non-serotonin reuptake inhibitors and postpartum hemorrhage could indicate that all antidepressants impact on risk of postpartum hemorrhage. We cannot rule out the possibility, however, that the results are confounded by unmeasured factors associated with the underlying disorders. While we did not hypothesize it a priori, it is possible that non-serotonin reuptake inhibitors could affect postpartum hemorrhage through pathways other than those potentially mediated by serotonin reuptake inhibition. Trazodone, a non-serotonin reuptake inhibitor, is a $5-\mathrm{HT}_{2 \mathrm{~A}}$ receptor antagonis $\mathrm{t}^{26}$ and serotonin induced myometrial contraction is mediated by this receptor, ${ }^{49}$ consequently blockade of the $5-\mathrm{HT}_{2 \mathrm{~A}}$ receptor could explain an association between trazodone use and atonic postpartum hemorrhage. It is possible that some of the positive findings are caused by chance. Overall, monotherapy with a non-serotonin reuptake inhibitor was rare in the cohort, comprising only $12.1 \%$ of antidepressant users. The results for non-serotonin reuptake inhibitors were much less precise than those for serotonin reuptake inhibitors, and some of the sensitivity analyses attenuated results toward the null, particularly for past use of non-serotonin reuptake inhibitors. It is possible that we failed to control for confounders that were particularly important among this group of women such as alcohol abuse or smoking. Bupropion, which is also indicated for smoking cessation, ${ }^{51}$ accounted for nearly $80 \%$ of current use of non-serotonin reuptake inhibitors. It is unclear, however, whether smoking is positively associated with postpartum hemorrhage. ${ }^{43-53}$

\section{Potential limitations}

Though adjustment for many measured potential confounders with standard multivariable regression and high dimensional propensity score analysis did not affect the results, the associations could reflect unmeasured confounding. Because the use of many antidepressants, not just serotonin reuptake inhibitors, near the time of delivery was associated with postpartum hemorrhage, it is possible that our results could potentially reflect residual confounding by unmeasured behavioral factors associated with depression and antidepressant use. These factors include inadequate diet and the use of tobacco, alcohol, and illegal drugs, ${ }^{54} 55$ which are inadequately captured by data on healthcare use. Although mood/anxiety disorders were not strongly associated with postpartum hemorrhage, it is possible that the unmeasured factors that are associated with the severity of the disorder could have confounded the results. Based on external adjustment, our results could have been attenuated slightly had we been able to adjust for body mass index (BMI). Residual confounding by use of over the counter aspirin is probably small, given the expected low prevalence of use in the third trimester. ${ }^{56}$ Misclassification of exposure is also a potential limitation because we cannot confirm that women were taking antidepressants on the days we assumed. ${ }^{57}$ No information was available regarding antidepressant use during admission to hospital, including the admission for delivery. We expect that this had a minimal impact on the misclassification of antidepressant use near the time of delivery because $95 \%$ of women delivered within one day of being admitted to hospital. Misclassification would be non-differential and would tend to attenuate the true association. The result including only women with the greatest amount of antidepressant coverage in the 90 days before delivery in the current exposure groups is reassuring because they were less likely to be affected by misclassification as these women were likely to have been taking antidepressants near the time of delivery. Furthermore, we did not have adequate power to examine the association between antidepressants and severe postpartum hemorrhage leading to blood transfusion or mortality. Finally, outcome misclassification is another source of bias, which would likely result in an underestimation of a true association. The following support the validity of the outcome definition. The positive predictive value for postpartum hemorrhage was $85 \%$ based on ICD-9 codes $666.0 x-666.2 x$ in discharge data from California hospitals. ${ }^{58}$ The magnitudes of association between well established risk factors for postpartum hemorrhage and postpartum hemorrhage were similar to those reported in previous studies. ${ }^{6-31}$ Moreover, the risk of postpartum hemorrhage was in line with US national statistics. ${ }^{5}$

\section{Generalizability of results}

This study was conducted among women enrolled in the US Medicaid program, which covers the healthcare of $40 \%$ of all pregnant women with deliveries in the US. ${ }^{59}$ Women in the cohort were low income, tended to be younger, and were more likely to be black compared with national figures for pregnant women. ${ }^{60}$ Nonetheless, the baseline risk of postpartum hemorrhage in our population was $2.9 \%$, which is similar to that of the general US population ${ }^{5}$ but lower than the risks reported for Canada and Australia. ${ }^{8}$ Results suggested that there was no association with non-serotonin reuptake inhibitors in older women. Because of the small numbers, however, this should be confirmed in another study. Furthermore, we found no evidence of effect modification by race or ethnicity. Based on these findings, we anticipate that the results will apply to other populations with a similar baseline risk for postpartum hemorrhage.

\section{Conclusions}

This study is the first to report an association between exposure to antidepressants at the time of delivery and risk of postpartum hemorrhage in a US population and in a population with a diagnosis of depression. The large study size permitted us to consider specific antidepressants, yet, despite the large cohort, there were still too few women with postpartum hemorrhage exposed to certain antidepressants, including trazodone and mirtazapine, to produce stable estimates. Also, the large size allowed us to define the primary exposure window as the 
delivery date, rather than using a wide window to gain enough cases for precise estimates, which can bias results downward.

Our study suggests that all classes of antidepressants are associated with an increased risk for abnormal bleeding. The magnitudes of association were in the range of those previously reported from Canadian and Swedish populations, ${ }^{19}{ }^{20}$ and we found that serotonin norepinephrine reuptake inhibitors and tricyclics were also associated with increased risk. Our findings regarding non-serotonin reuptake inhibitor antidepressants were unexpected and should be confirmed. Additional studies that account for clinical measures of severity of depression and behavioral factors associated with antidepressant use near the end of pregnancy are warranted to rule out the possibility that the associations with serotonin and non-serotonin reuptake inhibitors reflect confounding. Although we cannot rule out residual confounding, our study indicates that there might be about one excess case of postpartum hemorrhage for every 80 to 100 women using antidepressants near the time of delivery, if we assume causality. The absolute increase in risk associated with antidepressant exposure in the month before delivery is small, but women and their physicians should be aware of the potential risks when making treatment decisions near the end of pregnancy.

\section{Contributors: KP, SH-D, KFH, PLW, KBM, EDA, and SS were} responsible for conception and design. SH-D and SS acquired the data which were analyzed and interpreted by KP, SH-D, KFH, PLW, KBM, $\mathrm{HM}$, and SS. All authors critically revised the manuscript for important intellectual content. SH-D and SS obtaining funding. KP and HM provided administrative, technical, and material support. KP drafted the manuscript and is guarantor.

Funding: This work was supported by the Agency for Healthcare Research and Quality (AHRQ) (grant R01HS018533 to SH-D). KP was supported by training grant T32HD060454 in reproductive, perinatal, and pediatric epidemiology from the Eunice Kennedy Shriver National Institute of Child Health and Human Development, National Institutes of Health. SS was supported by a mid-career development award grant K02-HS017731 from the AHRQ. The AHRQ had no role in the study design and the collection, analysis, and interpretation of data and writing of the article and the decision to submit it for publication. Research was conducted independently of the sponsor and funders.

Ethical approval: This project was approved by Brigham and Women's Hospital and Harvard School of Public Health Institutional Review Boards and a data use agreement was approved by the Centers for Medicare and Medicaid Services (CMS).

Competing interests: All authors have completed the ICMJE uniform disclosure form at www.icmje.org/coi_disclosure.pdf (available on request from the corresponding author) and declare: the Pharmacoepidemiology Program at the Harvard School of Public Health receives funding from Pfizer and Asisa; SH-D has consulted for GSK and Novartis; EA received research funding from the National Institute on Alcohol Abuse and Alcoholism (NIAAA), the National Institute of Mental Health (NIMH), the National Institute on Drug Abuse (NIDA), Pfizer, Otsuka, Janssen, (all schizophrenia), Pine Rest Foundation (ECT/dementia), University of Chicago, Michigan State University, Pine Rest Foundation (depression screening tool, biomarkers of depression and suicidality), Novartis (antidepressant development), Pine Rest Foundation, AssureRx, Priority Health (pharmacogenomic testing in depression).

Data sharing: No additional data available.

Berg CJ, Callaghan WM, Syverson C, Henderson Z. Pregnancy-related mortality in the United States, 1998 to 2005. Obstet Gynecol 2010;116:1302-9.

2 ACOG Practice Bulletin: Clinical Management Guidelines for Obstetrician-Gynecologists Number 76, October 2006: postpartum hemorrhage. Obstet Gynecol 2006;108:1039-47.
3 Baskett TF, O'Connell CM. Severe obstetric maternal morbidity: a 15-year population-based study. J Obstet Gynaecol 2005;25:7-9.

4 Gilbert TT, Smulian JC, Martin AA, Ananth CV, Scorza W, Scardella AT. Obstetric admissions to the intensive care unit: outcomes and severity of illness. Obstet Gynecol 2003;102:897-903.

5 Callaghan WM, Kuklina EV, Berg CJ. Trends in postpartum hemorrhage: United States, 1994-2006. Am J Obstet Gynecol 2010;202:353.

6 Joseph KS, Rouleau J, Kramer MS, Young DC, Liston RM, Baskett TF. Investigation of an increase in postpartum haemorrhage in Canada. BJOG 2007;114:751-9.

7 Ford JB, Roberts CL, Simpson JM, Vaughan J, Cameron CA. Increased postpartum hemorrhage rates in Australia. Int $J$ Gynaecol Obstet 2007;98:237-43.

8 Knight M, Callaghan WM, Berg C, Alexander S, Bouvier-Colle MH, Ford JB, et al. Trends in postpartum hemorrhage in high resource countries: a review and recommendations from the International Postpartum Hemorrhage Collaborative Group. BMC Pregnancy Childbirth 2009;9:55.

9 Van Walraven C, Mamdani MM, Wells PS, Williams JI. Inhibition of serotonin reuptake by antidepressants and upper gastrointestinal bleeding in elderly patients: retrospective cohort study. BMJ 2001;323:655-8.

10 Meijer WE, Heerdink ER, Nolen WA, Herings RM, Leufkens HG, Egberts AC. Association of risk of abnormal bleeding with degree of serotonin reuptake inhibition by antidepressants. Arch Intern Med 2004;164:2367-70.

11 De Abajo FJ. Effects of selective serotonin reuptake inhibitors on platelet function: mechanisms, clinical outcomes and implications for use in elderly patients. Drugs Aging 2011;28:345-67.

12 Coupland C, Dhiman P, Morriss R, Arthur A, Barton G, Hippisley-Cox J. Antidepressant use and risk of adverse outcomes in older people: population based cohort study. BMJ 2011;343:d4551.

13 Castro VM, Gallagher PJ, Clements CC, Murphy SN, Gainer VS, Fava M, et al. Incident user cohort study of risk for gastrointestinal bleed and stroke in individuals with major depressive disorder treated with antidepressants. BMJ Open 2012;2:e000544.

14 Lee YC, Shau WY, Chang CH, Chen ST, Lin MS, Lai MS. Antidepressant use and the risk of upper gastrointestinal bleeding in psychiatric patients: a nationwide cohort study in Taiwan. J Clin Psychopharmacol 2012;32:518-24.

15 De Abajo FJ, Rodriguez LA, Montero D. Association between selective serotonin reuptake inhibitors and upper gastrointestinal bleeding: population based case-control study. BMJ 1999;319:1106-9.

16 Cooper WO, Willy ME, Pont SJ, Ray WA. Increasing use of antidepressants in pregnancy. Am J Obstet Gynecol 2007;196:544.

17 Andrade SE, Raebel MA, Brown J, Lane K, Livingston J, Boudreau D, et al. Use of antidepressant medications during pregnancy: a multisite study. Am J Obstet Gynecol 2008;198:194

18 Mitchell AA, Gilboa SM, Werler MM, Kelley KE, Louik C, Hernandez-Diaz S. Medication use during pregnancy, with particular focus on prescription drugs: 1976-2008. Am J Obstet Gynecol 2011;205:51

19 Salkeld E, Ferris LE, Juurlink DN. The risk of postpartum hemorrhage with selective serotonin reuptake inhibitors and other antidepressants. J Clin Psychopharmacol 2008;28:230-4.

20 Reis M, Kallen B. Delivery outcome after maternal use of antidepressant drugs in pregnancy: an update using Swedish data. Psychol Med 2010;40:1723-33.

21 Palmsten K, Huybrechts KF, Mogun H, Setoguchi S, Hernández-Díaz S. Harnessing the Medicaid Analytic eXtract (MAX) to evaluate medications in pregnancy: design considerations. PLOS ONE 2013;8:e67405. www.plosone.org/article/info\%3Adoi\%2F10. 1371\%2Fjournal.pone.0067405

22 Hubrechts KF, Palmsten K, Mogun H, Kowal M, Avorn J, Setoguchi-Iwata S, et al. National trends in antidepressant medication treatment among publicly insured pregnant women. Gen Hosp Psychiatry 2013;35:265-71.

23 Palmsten K, Huybrechts KF, Michels KB, Williams PL, Mogun H, Setoguchi S, et al. Antidepressant use and risk for preeclampsia. Epidemiology . 2013;24:682-91.

24 West SL, Richter A, Melfi CA, McNutt M, Nennstiel ME, Mauskopf JA. Assessing the Saskatchewan database for outcomes research studies of depression and its treatment. $J$ Clin Epidemiol 2000;53:823-31.

25 Oyelese Y, Ananth CV. Postpartum hemorrhage: epidemiology, risk factors, and causes. Clin Obstet Gynecol 2010;53:147-156.

26 O'Donnell JM, Shelton RC. Drug therapy of depression and anxiety disorders. In: Brunton LL, Chabner BA, Knollmann BC, eds. Goodman \& Gilman's the pharmacological basis of therapeutics. 12th ed. McGraw-Hill, 2011.

27 Tatsumi M, Groshan K, Blakely RD, Richelson E. Pharmacological profile of antidepressants and related compounds at human monoamine transporters. Eur $J$ Pharmacol 1997;340:249-58.

28 Owens MJ, Knight DL, Nemeroff CB. Second-generation SSRIs: human monoamine transporter binding profile of escitalopram and R-fluoxetine. Biol Psychiatry 2001;50:345-50.

29 Kuo F, Gillespie TA, Kulanthaivel P, Lantz RJ, Ma TW, Nelson DL, et al. Synthesis and biological activity of some known and putative duloxetine metabolites. Bioorg Med Chem Lett 2004;14:3481-6.

30 Magann EF, Evans S, Hutchinson M, Collins R, Howard BC, Morrison JC. Postpartum hemorrhage after vaginal birth: an analysis of risk factors. South Med J 2005:98:419-22.

31 Kramer MS, Dahhou M, Vallerand D, Liston R, Joseph KS. Risk factors for postpartum hemorrhage: can we explain the recent temporal increase? J Obstet Gynaecol Can 2011;33:810-9.

32 Schneeweiss S, Seeger JD, Maclure M, Wang PS, Avorn J, Glynn RJ. Performance of comorbidity scores to control for confounding in epidemiologic studies using claims data. Am J Epidemiol 2001:154:854-64.

33 Hernan MA, Hernandez-Diaz S, Werler MM, Mitchell AA. Causal knowledge as a prerequisite for confounding evaluation: an application to birth defects epidemiology. Am $J$ Epidemiol 2002;155:176-84.

34 Spiegelman D, Hertzmark E. Easy SAS calculations for risk or prevalence ratios and differences. Am J Epidemiol 2005;162:199-200.

35 Zou GY, Donner A. Extension of the modified Poisson regression model to prospective studies with correlated binary data. Stat Methods Med Res 2011 Nov 8, Epub ahead of print.

36 Rassen JA, Glynn RJ, Brookhart MA, Schneeweiss S. Covariate selection in high-dimensional propensity score analyses of treatment effects in small samples. Am J Epidemiol 2011;173:1404-13.

37 Rassen JA, Doherty M, Huang W, Schneeweiss S. Pharmacoepidemiology toolbox. www. hdpharmacoepi.org. 


\section{What is already known on this topic}

Use of serotonin reuptake inhibitor antidepressants is associated with an increased risk for gastrointestinal bleeding

\section{What this study adds}

Antidepressant use near the time of delivery is associated with an increased risk of postpartum hemorrhage Additional studies that account for clinical measures of depression severity and behavioral factors associated with depression are warranted

38 Ananth CV, VanderWeele TJ. Placental abruption and perinatal mortality with preterm delivery as a mediator: disentangling direct and indirect effects. Am J Epidemiol 2011;174:99-108.

39 Valeri L, VanderWeele TJ. Mediation analysis allowing for exposure-mediator interactions and causal interpretation: theoretical assumptions and implementation with SAS and SPSS macros. Psychol Methods 2013:18:137-50.

40 Walker AM. Observation and inference. Epidemiology Resources, 1991.

41 Schneeweiss $S$. Sensitivity analysis and external adjustment for unmeasured confounders in epidemiologic database studies of therapeutics. Pharmacoepidemiol Drug Safety 2006;15:291-303.

42 . National Health and Nutrition Examination Survey (NHANES). Analytic and reporting guidelines.National Center for Health Statistics, Centers for Disease Control and Prevention. 2005. www.cdc.gov/nchs/data/nhanes/nhanes_03_04/nhanes_analytic_ guidelines_dec_2005.pdf.

43 Blomberg M. Maternal obesity and risk of postpartum hemorrhage. Obstet Gynecol 2011;118:561-8.

44 Fyfe EM, Thompson JM, Anderson NH, Groom KM, McCowan LM. Maternal obesity and postpartum haemorrhage after vaginal and caesarean delivery among nulliparous women at term: a retrospective cohort study. BMC Pregnancy Childbirth 2012;12:112.

45 Thase ME. Effects of venlafaxine on blood pressure: a meta-analysis of original data from 3744 depressed patients. J Clin Psychiatry 1998;59:502-8.

46 Thase ME, Tran PV, Wiltse C, Pangallo BA, Mallinckrodt C, Detke MJ. Cardiovascular profile of duloxetine, a dual reuptake inhibitor of serotonin and norepinephrine. J Clin Psychopharmacol 2005;25:132-40.

47 Hernan MA, Hernandez-Diaz S, Robins JM. A structural approach to selection bias. Epidemiology 2004;15:615-25.

48 Andersen J, Kristensen AS, Bang-Andersen B, Stromgaard K. Recent advances in the understanding of the interaction of antidepressant drugs with serotonin and norepinephrine transporters. Chem Commun (Camb) 2009;25:3677-92.

49 Cordeaux Y, Pasupathy D, Bacon J, Charnock-Jones DS, Smith GC. Characterization of serotonin receptors in pregnant human myometrium. J Pharmacol Exp Ther 2009;328:682-91.

50 de Abajo FJ, Montero D, Rodriguez LA, Madurga M. Antidepressants and risk of upper gastrointestinal bleeding. Basic Clin Pharmacol Toxicol 2006;98:304-10.

51 Clark SM, Nakad R. Pharmacotherapeutic management of nicotine dependence in pregnancy. Obstet Gynecol Clin North Am 2011;38:297-311.
52 Guirgis RR, Clark AD, Hogston P, Golland IM, Bevan JR, Francis JG, et al. The effects of smoking on labour after uncomplicated pregnancy: a comparison between the progress and outcome of labour in 400 smokers and 400 matched non-smokers. J Obstet Gynaecol 1997;17:149-52.

53 Marchant S, Alexander J, Thomas P, Garcia J, Brocklehurst P, Keene J. Risk factors for hospital admission related to excessive and/or prolonged postpartum vaginal blood loss after the first $24 \mathrm{~h}$ following childbirth. Paediatr Perinat Epidemiol 2006;20:392-402.

54 Stewart D. Clinical practice. Depression during pregnancy. N Engl J Med 2011;365:1605-11.

55 Nonacs R, Cohen LS. Assessment and treatment of depression during pregnancy: an update. Psychiatr Clin North Am 2003;26:547-62.

56 Werler AA, Hernandez-Diaz S, Honein MA. Over-the-counter medications during pregnancy. Am J Obstet Gynecol 2005;193:771-7.

57 Stephansson O, Granath F, Svensson T, Haglund B, Ekbom A, Kieler H. Drug use during pregnancy in Sweden—assessed by the Prescribed Drug Register and the Medical Birth Register. Clin Epidemiol 2011;3:43-50.

58 Romano PS, Yasmeen S, Schembri ME, Keyzer JM, Gilbert WM. Coding of perineal lacerations and other complications of obstetric care in hospital discharge data. Obstet Gynecol 2005;106:717-25

59 Garcia G. Maternal and Child Health (MCH) Update: States Increase Eligibility for Children's Health in 2007. www.nga.org/files/live/sites/NGA/files/pdf/0811MCHUPDATE. PDF;jsessionid=7B47A647247DD4E5CB9B709C8F9797AE.

60 Martin JA, Hamilton BE, Ventura SJ, Osterman MJ. Wilson EC, Mathews TJ. Births: fina data for 2011. Natl Vital Stat Rep 2012;61:1-71.

Accepted: 25 July 2013

\section{Cite this as: BMJ 2013;347:f4877}

This is an Open Access article distributed in accordance with the Creative Commons Attribution Non Commercial (CC BY-NC 3.0) license, which permits others to distribute, remix, adapt, build upon this work non-commercially, and license their derivative works on different terms, provided the original work is properly cited and the use is non-commercial. See: http://creativecommons.org/licenses/by-nc/3.0/. 


\section{Tables}

Table 1 | Characteristics of pregnant women by exposure to antidepressants in US Medicaid Analytic eXtract. Figures are numbers (percentage) unless stated otherwise

\begin{tabular}{|c|c|c|c|c|c|c|c|}
\hline \multirow[b]{2}{*}{ Covariates } & \multirow[b]{2}{*}{$\begin{array}{l}\text { Unexposed } \\
(n=69044)\end{array}$} & \multicolumn{3}{|c|}{ SRI monotherapy ( $n=29$ 222) } & \multicolumn{3}{|c|}{ Non-SRI monotherapy $(n=4456)$} \\
\hline & & $\begin{array}{c}\text { Current }(\mathrm{n}=12 \\
710)\end{array}$ & Recent $(n=6096)$ & Past $(n=10416)$ & Current $(n=1495)$ & Recent $(n=829)$ & Past $(n=2132)$ \\
\hline \multicolumn{8}{|l|}{ Birth year: } \\
\hline 2000-02 & $16310(23.6)$ & $2780(21.9)$ & $1324(21.7)$ & $2180(20.9)$ & $242(16.2)$ & $141(17.0)$ & $399(18.7)$ \\
\hline 2003-04 & $18850(27.3)$ & $4382(34.5)$ & $1966(32.3)$ & 3367 (32.3) & $403(27.0)$ & $235(28.4)$ & $588(27.6)$ \\
\hline $2005-07$ & $33884(49.1)$ & $5548(43.7)$ & $2806(46.0)$ & $4869(46.8)$ & $850(56.9)$ & $453(54.6)$ & $1145(53.7)$ \\
\hline \multicolumn{8}{|l|}{ Region: } \\
\hline Northeast & $10884(15.8)$ & $1931(15.2)$ & $844(13.9)$ & $1340(12.9)$ & $198(13.2)$ & $108(13.0)$ & $257(12.1)$ \\
\hline South & $20712(30.0)$ & $3237(25.5)$ & $1793(29.4)$ & 3287 (31.6) & $438(29.3)$ & $254(30.6)$ & $737(34.6)$ \\
\hline Midwest & $24729(35.8)$ & $5448(42.9)$ & $2533(41.6$ & $4345(41.7)$ & $612(40.9)$ & $343(41.4)$ & $822(38.6)$ \\
\hline West & $12719(18.4)$ & 2094 (16.5) & $926(15.2)$ & $1444(13.9)$ & 247 (16.5) & $124(15.0)$ & $316(14.8)$ \\
\hline Median (IQR) age (years) & $23(20-27)$ & $25(22-30)$ & $24(21-29)$ & $24(21-28)$ & $26(22-31)$ & $25(21-29)$ & $24(21-28)$ \\
\hline \multicolumn{8}{|l|}{ Race: } \\
\hline White & $40543(58.7)$ & $10103(79.5)$ & 4471 (73.3) & $7149(68.6)$ & $1198(80.1)$ & $601(72.5)$ & $1546(72.5)$ \\
\hline Black & $15522(22.5)$ & $1027(8.1)$ & $801(13.1)$ & $1787(17.2)$ & $136(9.1)$ & $111(13.4)$ & $335(15.7)$ \\
\hline Hispanic & $8312(12.0)$ & $776(6.1)$ & $467(7.7)$ & $813(7.8)$ & $65(4.4)$ & $61(7.4)$ & $130(6.1)$ \\
\hline Other or unknown & $4667(6.8)$ & $804(6.3)$ & $357(5.9)$ & $667(6.4)$ & $96(6.4)$ & $56(6.8)$ & $121(5.7)$ \\
\hline Multiple pregnancy & $1275(1.9)$ & $218(1.7)$ & $113(1.9)$ & $213(2.0)$ & $36(2.4)$ & $19(2.3)$ & $39(1.8)$ \\
\hline $\begin{array}{l}\text { Diabetes diagnosis or } \\
\text { dispensing of antidiabetic }\end{array}$ & $5557(8.1)$ & $1392(11.0)$ & $678(11.1)$ & $930(8.9)$ & $152(10.2)$ & $76(9.2)$ & $219(10.3)$ \\
\hline $\begin{array}{l}\text { Hypertension diagnosis or } \\
\text { dispensing of } \\
\text { antihypertensive }\end{array}$ & $2694(3.9)$ & $800(6.3)$ & $373(6.1)$ & $588(5.7)$ & $89(6.0)$ & $47(5.7)$ & $116(5.4)$ \\
\hline Coagulopathy* & $440(0.6)$ & $99(0.8)$ & $47(0.8)$ & $95(0.9)$ & - & - & $17(0.8)$ \\
\hline $\begin{array}{l}\text { Any inpatient } \\
\text { mood/anxiety disorder } \\
\text { diagnosis }\end{array}$ & $3321(4.8)$ & $1077(8.5)$ & $631(10.4)$ & $960(9.2)$ & $115(7.7)$ & $75(9.1)$ & $175(8.2)$ \\
\hline $\begin{array}{l}\text { Median (IQR) No of } \\
\text { mood/anxiety diagnoses }\end{array}$ & $2(1-4)$ & $2(1-4)$ & $2(1-4)$ & $2(1-4)$ & $2(1-5)$ & $2(1-5)$ & $2(1-4)$ \\
\hline \multicolumn{8}{|c|}{ Other indications for antidepressant use: } \\
\hline Psychotic disorder & $808(1.2)$ & $176(1.4)$ & $98(1.6)$ & $187(1.8)$ & $28(1.9)$ & $11(1.3)$ & $39(1.8)$ \\
\hline $\begin{array}{l}\text { Other mental health } \\
\text { disorder }\end{array}$ & $2659(3.9)$ & $553(4.4)$ & $294(4.8)$ & $510(4.9)$ & $70(4.7)$ & $37(4.5)$ & $92(4.3)$ \\
\hline Pain related condition & $2109(3.1)$ & $705(5.6)$ & $332(5.5)$ & $624(6.0)$ & $75(5.0)$ & $38(4.6)$ & $111(5.2)$ \\
\hline Sleep disorder & $390(0.6)$ & $151(1.2)$ & $72(1.2)$ & $124(1.2)$ & $17(1.1)$ & $16(1.9)$ & $47(2.2)$ \\
\hline \multicolumn{8}{|l|}{ Other drug use at baseline: } \\
\hline Anticonvulsants & $1008(1.5)$ & $463(3.6)$ & $191(3.1)$ & $288(2.8)$ & $68(4.6)$ & $34(4.1)$ & $57(2.7)$ \\
\hline Benzodiazepines & $2330(3.4)$ & $1351(10.6)$ & $606(9.9)$ & $950(9.1)$ & $166(11.1)$ & $77(9.3)$ & $219(10.3)$ \\
\hline Aspirin* $^{*}$ & $141(0.2)$ & $32(0.3)$ & $20(0.3)$ & $43(0.4)$ & - & - & $13(0.6)$ \\
\hline Heparin $^{*}$ & $175(0.3)$ & $39(0.3)$ & $26(0.4)$ & $40(0.4)$ & - & - & - \\
\hline $\begin{array}{l}\text { Low molecular weight } \\
\text { heparin* }\end{array}$ & $267(0.4)$ & $69(0.5)$ & $26(0.4)$ & $54(0.5)$ & - & - & - \\
\hline Warfarin $^{*}$ & - & - & - & - & - & - & - \\
\hline $\begin{array}{l}\text { Median (IQR) No of } \\
\text { baseline outpatient visits }\end{array}$ & $14(11-19)$ & $14(11-20)$ & $14(11-19)$ & $14(11-19)$ & $15(11-20)$ & $15(11-20)$ & $15(11-20)$ \\
\hline $\begin{array}{l}\text { Any admissions to } \\
\text { hospital during baseline }\end{array}$ & $7426(10.8)$ & $1743(13.7)$ & $965(15.8)$ & $1633(15.7)$ & $191(12.8)$ & $114(13.8)$ & $308(14.5)$ \\
\hline
\end{tabular}


Table 1 (continued)

\begin{tabular}{|c|c|c|c|c|c|c|c|}
\hline \multirow[b]{2}{*}{ Covariates } & \multirow[b]{2}{*}{$\begin{array}{l}\text { Unexposed } \\
(n=69044)\end{array}$} & \multicolumn{3}{|c|}{ SRI monotherapy ( $n=29$ 222) } & \multicolumn{3}{|c|}{ Non-SRI monotherapy $(n=4456)$} \\
\hline & & $\begin{array}{c}\text { Current }(n=12 \\
710)\end{array}$ & Recent $(n=6096)$ & Past ( $n=10416)$ & Current $(n=1495)$ & Recent ( $n=829)$ & Past $(n=2132)$ \\
\hline In hospital & $62351(90.3)$ & $11594(91.2)$ & $5622(92.2)$ & $9452(90.8)$ & $1370(91.6)$ & $748(90.2)$ & $1952(91.6)$ \\
\hline $\begin{array}{l}\text { Delivery within } 1 \text { day of } \\
\text { admission } \dagger\end{array}$ & $59400(95.8)$ & $1107(95.8)$ & $5292(6.0)$ & $8940(94.6)$ & $1304(95.2)$ & $705(94.3)$ & $1858(95.2)$ \\
\hline Short labor & $1724(2.5)$ & $423(3.3)$ & $180(3.0)$ & $305(2.9)$ & $54(3.6)$ & $15(1.8)$ & $52(2.4)$ \\
\hline Long labor & $1620(2.4)$ & $303(2.4)$ & $146(2.4)$ & $233(2.2)$ & $30(2.0)$ & $18(2.2)$ & $51(2.4)$ \\
\hline Labor induction & $8422(12.2)$ & $1530(12.0))$ & $774(12.7)$ & $1332(12.8)$ & $210(14.1)$ & $98(11.8)$ & $301(14.1)$ \\
\hline $\begin{array}{l}\text { Forceps or vacuum } \\
\text { delivery }\end{array}$ & $3913(5.7)$ & $729(5.7)$ & $332(5.5)$ & $556(5.3)$ & $70(4.7)$ & $37(4.5)$ & $103(4.8)$ \\
\hline
\end{tabular}

$I Q R=$ interquartile range; $S R I=s e r o t o n i n$ reuptake inhibitor.

${ }^{*}$ Cell sizes too small for display per Centers for Medicare and Medicaid Services cell size suppression policy.

†Excludes women who delivered outside hospital. 
Table 2| Relative risks (RR) and 95\% confidence intervals (Cl) comparing risk for postpartum hemorrhage in pregnant women exposed to antidepressants

\begin{tabular}{|c|c|c|c|c|}
\hline \multirow[b]{2}{*}{ Exposure Group } & \multirow[b]{2}{*}{ Total } & \multirow{2}{*}{$\begin{array}{l}\text { No }(\%) \text { of women with } \\
\text { postpartum hemorrhage }\end{array}$} & \multicolumn{2}{|c|}{ RR $(95 \%$ Cl) } \\
\hline & & & Adjusted for delivery year* & Fully adjusted $\dagger$ \\
\hline \multicolumn{5}{|l|}{ SRI monotherapy: } \\
\hline Current & 12710 & $503(4.0)$ & $1.44(1.30$ to 1.58$)$ & 1.47 (1.33 to 1.62$)$ \\
\hline Recent & 6096 & $196(3.2)$ & $1.17(1.01$ to 1.35$)$ & 1.19 (1.03 to 1.38$)$ \\
\hline Past & 10416 & $264(2.5)$ & $0.92(0.81$ to 1.05$)$ & $0.93(0.82$ to 1.06$)$ \\
\hline \multicolumn{5}{|c|}{ Non-SRI monotherapy: } \\
\hline Current & 1495 & $56(3.8)$ & $1.36(1.05$ to 1.77$)$ & $1.39(1.07$ to 1.81$)$ \\
\hline Recent & 829 & $26(3.1)$ & 1.15 (0.79 to 1.68$)$ & $1.17(0.80$ to 1.70$)$ \\
\hline Past & 2132 & $73(3.4)$ & $1.24(0.99$ to 1.56$)$ & $1.26(1.00$ to 1.59$)$ \\
\hline Unexposed & 69044 & $1896(2.8)$ & Reference & Reference \\
\hline
\end{tabular}

$\mathrm{SRI}=$ serotonin reuptake inhibitors.

*2000-01, 2002, 2003, 2004, 2005, 2006, 2007.

†Delivery year, age, race, multiple pregnancy, diabetes, coagulopathy, number of outpatient mood/anxiety disorder diagnoses, number of inpatient mood/anxiety disorder diagnoses, psychotic disorder, other mental health disorder, pain indication, sleep disorder, anticonvulsant dispensing, benzodiazepine dispensing, aspirin dispensing, heparin dispensing, low molecular weight heparin dispensing, warfarin dispensing, and number of outpatient visits and days in hospital during baseline. 
Table 3 | High dimensional propensity score analysis*. Figures are odds ratios and $95 \%$ confidence intervals adjusted for 10ths of propensity score, comparing risk for postpartum hemorrhage in pregnant women with current antidepressant exposure

\begin{tabular}{|c|c|c|c|c|c|}
\hline & \multirow[b]{2}{*}{ Total† } & \multirow{2}{*}{$\begin{array}{c}\text { No }(\%) \text { of women with } \\
\text { postpartum } \\
\text { hemorrhage }\end{array}$} & \multicolumn{3}{|c|}{ Covariates in propensity score model } \\
\hline & & & Delivery year & Investigator defined‡ & $\begin{array}{l}\text { Investigator defined } \neq \text { and } \\
\text { empirically defined }\end{array}$ \\
\hline SRI monotherapy & 10203 & $415(4.1)$ & 1.46 (1.32 to 1.61$)$ & 1.47 (1.32 to 1.64$)$ & $1.52(1.35$ to 1.71$)$ \\
\hline Unexposed & 53348 & $1479(2.8)$ & Reference & Reference & Reference \\
\hline Non-SRI monotherapy & 1162 & $45(3.9)$ & 1.39 (1.06 to 1.82$)$ & 1.49 (1.12 to 1.98$)$ & 1.39 (1.03 to 1.89$)$ \\
\hline Unexposed & 52192 & $1475(2.8)$ & Reference & Reference & Reference \\
\hline
\end{tabular}

SRI=serotonin reuptake inhibitor.

*Women with highest and lowest $2.5 \%$ of propensity score excluded from analyses.

$\dagger$ Numbers are for trimmed population in investigator defined and empirically defined covariates analysis.

‡Investigator defined covariates: delivery year, age, race, multiple pregnancy, diabetes, coagulopathy, number of outpatient mood/anxiety disorder diagnoses, number of inpatient mood/anxiety disorder diagnoses, psychotic disorder, other mental health disorder, pain indication, sleep disorder, anticonvulsant dispensing, benzodiazepine dispensing, aspirin dispensing, heparin dispensing, low molecular weight heparin dispensing, and number of outpatient visits and days in hospital during baseline. 
Table 4| Fully adjusted ${ }^{*}$ relative risks (RR) and $95 \%$ confidence intervals (Cl) comparing risk for postpartum hemorrhage by specific antidepressants; restricted to women with serotonin reuptake inhibitor (SRI) or non-SRI monotherapy

\begin{tabular}{|c|c|c|c|}
\hline Specific antidepressants & Total & $\begin{array}{l}\text { No }(\%) \text { of women with postpartum } \\
\text { hemorrhage }\end{array}$ & RR $(95 \% \mathrm{Cl})$ \\
\hline \multicolumn{4}{|l|}{ Paroxetine: } \\
\hline Current & 2055 & $77(3.8)$ & 1.36 (1.09 to 1.71$)$ \\
\hline Recent & 962 & $40(4.2)$ & 1.52 (1.12 to 2.07 ) \\
\hline Past & 1617 & $49(3.0)$ & $1.13(0.85$ to 1.49$)$ \\
\hline \multicolumn{4}{|l|}{ Sertraline: } \\
\hline Current & 4526 & $162(3.6)$ & 1.31 (1.12 to 1.54$)$ \\
\hline Recent & 2266 & $78(3.4)$ & 1.27 (1.01 to 1.59$)$ \\
\hline Past & 3812 & $85(2.2)$ & 0.82 (0.66 to 1.01$)$ \\
\hline \multicolumn{4}{|l|}{ Fluoxetine: } \\
\hline Current & 3322 & $137(4.1)$ & 1.51 (1.27 to 1.79$)$ \\
\hline Recent & 1628 & $50(3.1)$ & $1.14(0.86$ to 1.50$)$ \\
\hline Past & 3075 & $78(2.5)$ & $0.93(0.75$ to 1.17$)$ \\
\hline \multicolumn{4}{|l|}{ Escitalopram: } \\
\hline Current & 1022 & $43(4.2)$ & 1.56 (1.16 to 2.09$)$ \\
\hline Recent & 520 & $14(2.7)$ & 1.01 (0.61 to 1.70$)$ \\
\hline Past & 940 & $24(2.6)$ & 0.96 (0.64 to 1.42$)$ \\
\hline \multicolumn{4}{|l|}{ Citalopram: } \\
\hline Current & 891 & $36(4.0)$ & 1.48 (1.07 to 2.04$)$ \\
\hline Recent† & 462 & - & 0.70 (0.37 to 1.34$)$ \\
\hline Past & 830 & $17(2.1)$ & 0.76 (0.47 to 1.23$)$ \\
\hline \multicolumn{4}{|l|}{ Amitriptyline: } \\
\hline Current† & 176 & - & 1.68 (0.89 to 3.16$)$ \\
\hline Recent† & 69 & - & 1.13 (0.29 to 4.42$)$ \\
\hline Past & 206 & - & 1.08 (0.48 to 2.42$)$ \\
\hline \multicolumn{4}{|l|}{ Venlafaxine: } \\
\hline Current & 763 & $46(6.0)$ & 2.24 (1.69 to 2.97 ) \\
\hline Recent† & 237 & - & $1.10(0.53$ to 2.30$)$ \\
\hline Past & 458 & $12(2.6)$ & 0.98 (0.56 to 1.70$)$ \\
\hline \multicolumn{4}{|l|}{ Trazodone: } \\
\hline Currentt & 139 & - & 1.85 (0.90 to 3.80$)$ \\
\hline Recent† & 73 & - & 2.01 (0.77 to 5.24 ) \\
\hline Pastt & 226 & - & 0.61 (0.23 to 1.67$)$ \\
\hline \multicolumn{4}{|l|}{ Bupropion: } \\
\hline Current & 1162 & $42(3.6)$ & 1.32 (0.98 to 1.79$)$ \\
\hline Recent & 660 & $21(3.2)$ & 1.17 (0.77 to 1.79 ) \\
\hline Past & 1712 & $61(3.6)$ & 1.32 (1.02 to 1.69$)$ \\
\hline \multicolumn{4}{|l|}{ Mirtazapine: } \\
\hline Current† & 129 & - & 0.87 (0.29 to 2.66 ) \\
\hline Recent & 57 & 0 & - \\
\hline Pastt & 135 & - & 1.07 (0.40 to 2.82$)$ \\
\hline No exposure & 69044 & $1896(2.8)$ & Reference \\
\hline
\end{tabular}

*Delivery year, age, race, multiple pregnancy, diabetes, coagulopathy, number of mood/anxiety disorder diagnoses, number of inpatient mood/anxiety disorder diagnoses, psychotic disorder, other mental health disorder, pain indication, sleep disorder, anticonvulsant dispensing, benzodiazepine dispensing, aspirin dispensing, heparin dispensing, low molecular weight heparin dispensing, number of outpatient visits and days in hospital during baseline, and for other specific antidepressants within each time period, including those listed above and clomipramine, duloxetine, imipramine, nortriptyline, doxepin, and nefazodone. †Cell sizes are too small for display per Centers for Medicare and Medicaid Services cell size suppression policy. 
Table 5 Fully adjusted ${ }^{\star}$ relative risks (RR) and $95 \%$ confidence intervals $(\mathrm{Cl})$ comparing risk for postpartum hemorrhage in pregnant women with exposure to antidepressants by alternative exposure groups

\begin{tabular}{|c|c|c|c|}
\hline & Total & $\begin{array}{l}\text { women with } p \\
\text { hemorrhage }\end{array}$ & RR $(95 \% \mathrm{Cl})$ \\
\hline \multicolumn{4}{|c|}{ All antidepressants: } \\
\hline Current & 16029 & $620(3.9)$ & 1.44 (1.32 to 1.58$)$ \\
\hline Recent & 7577 & 247 (3.3) & 1.21 (1.06 to 1.38$)$ \\
\hline Past & 13350 & $357(2.7)$ & $0.98(0.88$ to 1.10$)$ \\
\hline \multicolumn{4}{|c|}{ Antidepressant classes } \\
\hline \multicolumn{4}{|c|}{ SSRI monotherapy: } \\
\hline Current & 11516 & $440(3.8)$ & $1.42(1.27$ to 1.57$)$ \\
\hline Recent & 5706 & $186(3.3)$ & $1.21(1.04$ to 1.40$)$ \\
\hline Past & 9675 & $244(2.5)$ & 0.93 (0.81 to 1.06$)$ \\
\hline \multicolumn{4}{|c|}{ SNRI monotherapy: } \\
\hline Current & 702 & $35(5.0)$ & 1.90 (1.37 to 2.63$)$ \\
\hline Recent $†$ & 217 & - & 1.21 (0.58 to 2.54$)$ \\
\hline Past & 423 & $12(2.8)$ & 1.05 (0.60 to 1.83$)$ \\
\hline \multicolumn{4}{|c|}{ Tricyclic monotherapy: } \\
\hline Current† & 175 & - & $1.77(0.90$ to 3.47$)$ \\
\hline Recent† & 75 & - & 0.51 (0.08 to 3.40$)$ \\
\hline Past & 245 & - & $1.37(0.72$ to 2.61$)$ \\
\hline \multicolumn{4}{|c|}{ Bupropion monotherapy: } \\
\hline Current & 1114 & $40(3.6)$ & $1.32(0.97$ to 1.80$)$ \\
\hline Recent & 649 & $21(3.2)$ & 1.20 (0.79 to 1.83$)$ \\
\hline Past & 1666 & $60(3.6)$ & $1.33(1.03$ to 1.71$)$ \\
\hline \multicolumn{4}{|c|}{ Other monotherapy: } \\
\hline Current† & 251 & - & $1.37(0.72$ to 2.60$)$ \\
\hline Recent $†$ & 134 & - & 1.13 (0.43 to 2.95$)$ \\
\hline Past & 344 & - & $0.85(0.42$ to 1.71$)$ \\
\hline Unexposed & 69044 & $1896(2.8)$ & Reference \\
\hline
\end{tabular}

*Delivery year, age, race, multiple pregnancy, diabetes, coagulopathy, number of outpatient mood/anxiety disorder diagnoses, number of inpatient mood/anxiety disorder diagnoses, psychotic disorder, other mental health disorder, pain indication, sleep disorder, anticonvulsant dispensing, benzodiazepine dispensing, aspirin dispensing, heparin dispensing, low molecular weight heparin dispensing, warfarin dispensing, and number of outpatient visits and days in hospital during baseline. †Cell sizes too small for display per Centers for Medicare and Medicaid Services cell size suppression policy. 
Table 6 | Fully adjusted ${ }^{*}$ relative risks (RR) and $95 \%$ confidence intervals (Cl) comparing risk for postpartum hemorrhage among pregnant women with current exposure by dose†

\begin{tabular}{lccc} 
& Total & No (\%) of women with postpartum & RR (95\% Cl) \\
hemorrhage & & $1.55(1.21$ to 1.97$)$ \\
\hline High monotherapy: & 1597 & $66(4.1)$ & $1.51(1.34$ to 1.70$)$ \\
\hline Medium & 7877 & $324(4.1)$ & $1.29(1.07$ to 1.55$)$ \\
\hline Low & 3236 & $113(3.5)$ & $1.07(0.61$ to 1.88$)$ \\
\hline Non-SRI monotherapy: & 419 & $12(2.9)$ & $1.49(1.11$ to 2.00$)$ \\
\hline Medium or high & 1074 & $44(4.1)$ & Reference
\end{tabular}

SRI=serotonin reuptake inhibitor.

*Delivery year, age, race, multiple pregnancy, diabetes, coagulopathy, number of outpatient mood/anxiety disorder diagnoses, number of inpatient mood/anxiety disorder diagnoses, psychotic disorder, other mental health disorder, pain indication, sleep disorder, anticonvulsant dispensing, benzodiazepine dispensing, aspirin dispensing, heparin dispensing, low molecular weight heparin dispensing, and number of outpatient visits and days in hospital during baseline.

†Dose levels were defined according to Goodman \& Gilman's usual dose (mg/day) $:^{26}$ low $<$ lowest usual dose, medium $\leq$ midpoint of usual dose range, high $>$ midpoint of usual dose range. 


\section{Figures}

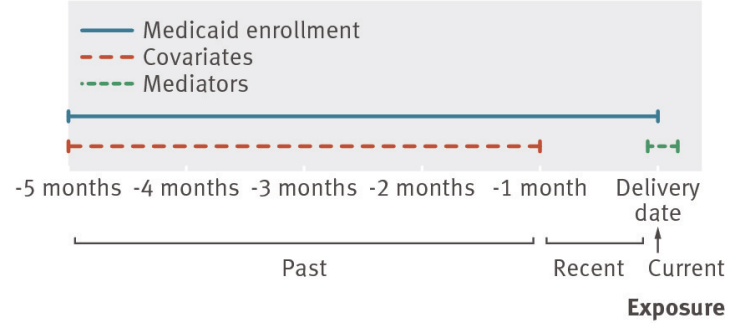

Fig 1 Timeline of study. Months are before delivery date (for example, -5 months is 5 months before delivery date)

Serotonin reuptake inhibitors

Primary estimate

Cohort with or without mood/anxiety disorders*

Cohort with stricter eligibility criteriat

Cohort without hypertension or antihypertensives

Cohort with diagnostic codes specific to depression

Atonic PPH

Inpatient PPH

$\geq 75 \%$ of 90 days before delivery covered by ADs

$A D$ dispensing $<14$ days before delivery

Restricted to women 130 years old

Restricted to women $\geq 30$ years old

Non-serotonin reuptake inhibitors

Primary estimate

Cohort with or without mood/anxiety disorders* Cohort with stricter eligibility criteriat

Cohort without hypertension or antihypertensives

Cohort with diagnostic codes specific to depression

Atonic PPH

Inpatient $\mathrm{PPH}$

$\geq 75 \%$ of 90 days before delivery covered by ADs

$A D$ dispensing 14 days before delivery

Restricted to women $<30$ years old

Restricted to women $\geq 30$ years old

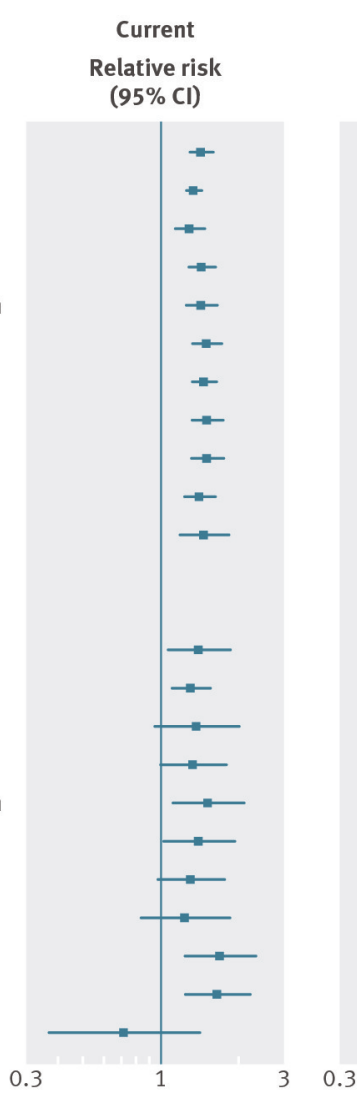

Recent

Relative risk

$(95 \% \mathrm{Cl})$

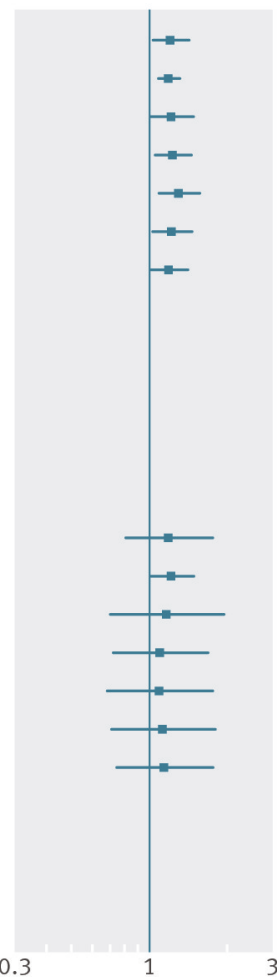

Past

Relative risk $(95 \% \mathrm{Cl})$

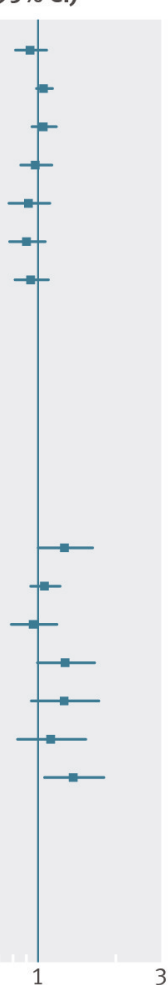

Fig 2 Primary and sensitivity analyses with adjusted relative risks and 95\% confidence intervals comparing risk for postpartum hemorrhage (PPH) in women with exposure to antidepressants (AD) in pregnancy. ${ }^{*}$ Odds ratios estimated without adjustment for correlation among multiple pregnancies in same women because of computing limitations. †Restricted to women who had mood/anxiety disorders and met Medicaid enrollment and eligibility requirements throughout pregnancy 